\title{
TERRITÓRIOS CRIATIVOS: ATIVIDADES DOS PONTOS DE CULTURA
}

\section{DE NATAL-RN}

\author{
Marcel Lúcio Matias Ribeiro ${ }^{1}$ \\ Nara da Cunha Pessoa ${ }^{2}$ \\ Fernanda Ferreira da Silva ${ }^{3}$ \\ Rafaela Felipe Fagundes da Silva ${ }^{4}$
}

Resumo: O presente trabalho tem como objetivo apresentar as primeiras informações obtidas no projeto de extensão intitulado "Territórios criativos: a dimensão econômica dos Pontos de Cultura de Natal", desenvolvido por professores e alunos do Curso de Produção Cutural do IFRN. Neste trabalho, priorizamos as principais atividades desenvolvidas pelos dez Pontos que foram sensibilizados e aderiram ao projeto, pensando em sua sustentabilidade, para além do repasse de verbas do Programa Cultura Viva. Em uma análise inicial, percebermos que em Natal os Pontos atuam de forma desarticulada, não sendo possível visualizar, nesse momento, uma rede de economia solidária entre eles.

Palavras-chave: Programa Cultura Viva. Ponto de Cultura. Sustentabilidade. Territórios criativos.

Abstract: This paper intents to present the first informations about the extension project named "Creative territories: the economic dimension of the Pontos de Cultural of Natal", developed by professsors and students of the Cultural Management course from IFRN. In this work our priority is to analyse the main activities of the ten "Pontos de Cultura" that we reach and had participating in our project. This moment will be to think about their sustentability for beyond the resources from de program

\footnotetext{
${ }^{1}$ Doutor em Literatura Comparada pela UFRN. Professor do IFRN - Campus Natal Cidade Alta. email: marcel.matias@ifrn.edu.br.

2 Mestre em Ciências Sociais pela UFRN. Professora do IFRN - Campus Natal Cidade Alta. e-mail: ncpessoa@yahoo.com.br.

3 Graduanda em Produção Cultural pelo IFRN - Campus Natal Cidade Alta. Bolsista de Extensão do IFRN. e-mail: fnandaproducao@gmail.com.

${ }^{4}$ Graduanda em Produção Cultural pelo IFRN - Campus Natal Cidade Alta. Bolsista de Extensão do IFRN. e-mail: rafinha.faguh@gmail.com.
} 
"Cultura Viva". In our initial analysis we realized that in Natal the "Pontos de Cultura" activities do not allow them to have a net of solidary economy.

Keywords: Program "Cultura Viva". "Pontos de Cultura". Sustentability. Creative territories.

\section{INTRODUÇÃO}

O Programa Nacional de Cultura, Educação e Cidadania - Cultura Viva, criado em 2004, faz parte de um novo momento do Ministério da Cultura (MinC), em consonância com as mudanças de atuação do Estado brasileiro via políticas públicas. A partir de 2003, as demandas sociais passaram a ser colocadas na pauta do Governo Federal. Na pasta da cultura, políticas públicas foram viabilizadas através de programas, como o Cultura Viva, e de leis, como as que implementam o Sistema Nacional de Cultura e o Plano Nacional de Cultura.

A participação social, através de debates, conferências e consultas públicas, consolidaram uma política com características mais democráticas, aspecto que, na área cultural, foi, certamente, um divisor de águas. Além disso, a ampliação do conceito de cultura foi fundamental para que o MinC pudesse atuar em locais antes relegados ao abandono, e, para tanto, foi preciso também incorporar, ao conceito antropológico de cultura, três dimensões transversais e fundamentais à cultura: a simbólica, a cidadã e a econômica. Em resumo, sobre as transformações ocorridas:

[...] vale destacar 1) o alargamento do conceito de cultura e a inclusão do direito à cultura, como um dos princípios basilares da cidadania; sendo assim, 2) o público alvo das ações governamentais é deslocado do artista para a população em geral; e 3) o Estado, então, retoma o seu lugar como agente principal na execução das políticas culturais; ressaltando a importância 4) da participação da sociedade na elaboração dessas políticas; e 5) da divisão de responsabilidades entre os diferentes níveis de governo, as organizações sociais e a sociedade, para a gestão das ações. (CANEDO et al., 2010, p. 30)

Neste contexto, ao ser criado, o Programa Cultura Viva (PCV) deveria enfrentar alguns problemas que estavam diretamente relacionados às características culturais e sociais peculiares das comunidades em situação de vulnerabilidade. Esses problemas podem ser sintetizados nos seguintes enunciados: 
1. Ausência de estímulos para o uso das potencialidades artísticas e culturais locais como a experiência lúdica e de integração social;

2. Carência de meios para divulgação das produções e expressões culturais locais;

3. Dificuldades de acesso das comunidades à produção artística, na condição de público fruidor de entretenimento, conhecimento e lazer;

4. Dificuldades de acesso à cultura digital;

5. Limitações de acesso a processos educativos que respeitem as contingências culturais locais. (SILVA, 2007, p. 275)

Para dirimir esses problemas, o MinC adotou como principais diretrizes os princípios de autonomia, protagonismo e empoderamento dos grupos culturais. E, para que isso acontecesse na prática, criou a principal ação do PCV: os Pontos de Cultura, que, por sua vez, têm como principais características a democratização, do acesso e da produção, e a valorização das experiências locais e da diversidade cultural (LACERDA; MARQUES; ROCHA, 2010).

Os Pontos de Cultura são entidades sem fins lucrativos que desenvolvem ações culturais continuadas nas comunidades locais (MINC, 2014) ${ }^{5}$ Contudo, ao nos apropriarmos de modo mais aprofundado da proposta, compreendemos que a ideia dos Pontos de Cultura é algo muito mais amplo e complexo. De acordo com o seu idealizador, o historiador e escritor Célio Turino,

Ponto de Cultura é um conceito de política pública. São organizações culturais da sociedade que ganham força e reconhecimento institucional ao estabelecer uma parceria, um pacto, com o Estado. Aqui há uma sutil distinção: o Ponto de Cultura não pode ser para as pessoas, e sim das pessoas; um organizador da cultura no nível local, atuando como um ponto de recepção e irradiação de cultura. Como um elo na articulação em rede, o Ponto de Cultura não é um equipamento cultural do governo, nem um serviço. Seu foco não está na carência, na ausência de bens e serviços, e sim na potência, na capacidade de agir de pessoas e grupos. Ponto de Cultura é cultura em processo, desenvolvida com autonomia e protagonismo social. (TURINO, 2010, p. 64)

Os Pontos de Cultura podem ser espaços já existentes, anteriores ao edital do MinC, ou não. Em uma avaliação inicial ao PCV, no decorrer dos anos de $2007 \mathrm{e}$ 2008, o IPEA trouxe como um dos resultados que 63\% dos espaços físicos já existiam

\footnotetext{
${ }^{5}$ Disponível em: <http://www.cultura.gov.br/cultura-viva1>. Acesso em: 31 out. 2014.
} 
antes do PCV e 37\% derivaram do processo de conveniamento (ARAÚJO; SILVA, 2010, p. 107). Nesse sentido, é possível imaginarmos que os espaços existentes antes mesmo do convênio com o MinC possuíam alguma sustentabilidade para o desenvolvimento de suas atividades, a partir de uma administração, por mínima que fosse.

Em Natal, todos os dez Pontos de Cultura visitados já desenvolviam ações antes de serem conveniados ao MinC ou junto a parceria do MinC com a Fundação de Cultura do Rio Grande do Norte, Fundação José Augusto (FJA).

Para além da existência do espaço de cultura, anterior ou não ao PCV, os Pontos de Cultura devem desenvolver múltiplas atividades que vão desde a criação artística até a capacitação de profissionais da área, passando pelo desenvolvimento e a comercialização de produtos, não tendo "um modelo único de instalações físicas, de programação ou de atividades" (ARAÚJO; SILVA, 2010, p. 40). Os Pontos de Cultura existem a partir de uma realidade local, e, ao mesmo tempo, de acordo com o repertório cultural de determinado grupo. Assim, cada Ponto é diferente do outro, embora possam desenvolver atividades parecidas.

Os pontos de cultura dinamizam ações diversas de fomento à inclusão produtiva que podem ser identificadas tanto a partir do estímulo a setores produtivos específicos (artesanato, costura, música, dentre outros) quanto a sistemas produtivos mais amplos (da música, da tecelagem, do audiovisual, etc.). (VILUTIS, 2011, p. 6)

Este trabalho tem como objetivo apresentar os resultados iniciais obtidos ao longo dos cinco primeiros meses do Projeto de Extensão “Territórios criativos: a dimensão econômica dos Pontos de Cultura de Natal". ${ }^{6}$ Nesse momento, focalizamos a descrição e a análise das atividades desenvolvidas pelos dez Pontos sensibilizados nesses meses, sem, contudo, nos distanciarmos da problemática inicial do projeto. A principal motivação do projeto é conhecer e auxiliar as atividades desenvolvidas pelos Pontos de Cultura que lhes garantam ou que tenham potencial para garantir a sua sustentabilidade, inclusive financeira. Nesse sentido, os Pontos de Cultura são aqui pensados enquanto Territórios Criativos.

\footnotetext{
${ }^{6}$ Projeto de extensão do Curso Superior de Tecnologia em Produção Cultural do Instituto Federal de Educação, Ciência e Tecnologia do Rio Grande do Norte, Campus Natal-Cidade Alta, iniciado em junho de 2014.
} 
Os Territórios Criativos podem ser tanto bairros quanto polos produtivos, cidades ou bacias. Dentre esses, o menor espaço é o polo criativo compreendido como um "conjunto de empreendimentos criativos geograficamente próximos e circunscritos a um território de pequena dimensão" (BRASIL, 2011, p. 68). De acordo com o MinC (2011), esses espaços também devem ter pontencial para a geração de trabalho, emprego e renda.

Para nós, os Pontos de Cultura são territórios talvez menores que os polos, mas que possuem aspectos que os definem como territórios criativos, sobretudo o potencial que têm para a transformação local, através da produção da cultura, do empoderamento e da capacitação da população, do acesso à cultura, do consumo da cultura e da ampliação de repertório e de diálogos, a partir da valorização da diversidade cultural.

\section{DE PONTOS DE CULTURA A TERRITÓRIOS CRIATIVOS}

Para reconhecermos os Pontos de Cultura como territórios criativos é necessário que apresentemos alguns conceitos adotados recentemente que nos permitem compreender de forma mais aprofundada esses espaços. É igualmente fundamental que nos familiarizemos com as pesquisas realizadas sobre o PCV.

Ao mergulharmos na proposta do PCV e no entendimento adotado pelo MinC, sobre economia criativa e territórios criativos, buscamos conhecimento em muitas publicações. Nossas principais fontes de referência para esse aprofundamento teórico foram as publicações (2011) e o relatório de avaliação do Instituto de Pesquisa Econômica Aplicada (2010), publicações do próprio MinC, como o estudo sobre Polos Criativos (2012), o Plano da Secretaria da Economia Criativa (2011) e o Documento Base do PCV (2013), além de artigos publicados on-line pela Fundação Casa de Rui Barbosa (acessados em 2014), capítulos de livros (CANEDO et al., 2010; LACERDA; MARQUES; ROCHA, 2010), dissertações de mestrado sobre o PCV (DOMINGUES, 2008; DINIZ, 2009) e o artigo (2005) e livro (2010) de Célio Turino, também sobre o PCV.

Em 2011, o MinC criou a Secretaria da Economia Criativa (SEC) e lançou o seu plano de gestão para o período de 2011 a 2014. Naquele momento, a SEC enfrentou um desafio que permanence presente nas discussões sobre economia criativa ainda hoje: o conceito de economia criativa e sua área de abrangência. Para a 
SEC,

[...] os setores criativos são aqueles cujas atividades produtivas têm como processo principal um ato criativo gerador de um produto, bem ou serviço, cuja dimensão simbólica é determinante do seu valor, resultando em produção de riqueza cultural, econômica e social. (BRASIL, 2011, p. 22)

Como é possível percebermos, a SEC entende que os setores criativos resultam em muito mais do que desenvolvimento econômico ampliando a atuação desses setores nas áreas cultural e social. Os principíos norteadores da economia criativa brasileira comprovam isso: a diversidade cultural, a sustentabilidade, a inovação e a inclusão social (BRASIL, 2011).

Diante desses quatro princípios, é possível estabelecermos relação direta com alguns dos objetivos do PCV e, mais especificamente, com os Pontos de Cultura. Acreditamos, portanto, que há uma aproximação entre a economia criativa brasileira e os Pontos de Cultura.

De acordo com o relatório de avaliação do PCV, o programa "articula associações da sociedade civil e tem conseguido, com certo êxito, proporcionar o acesso destes agentes a recursos públicos, facultando fortalecimento e reconhecimento de circuitos culturais com bases comunitárias e associativas" (ARAÚJO; SILVA, 2010, p. 38). Assim, os principais aspectos do programa podem ser sintetizados no Quadro 1, a seguir.

Quadro 1 - Principais aspectos do Programa Cultura Viva

\begin{tabular}{|c|l|}
\hline Problema & $\begin{array}{l}\text { A desvalorização da produção cultural dos grupos e comunidades e } \\
\text { sua exclusão dos meios de produção, fruição e difusão cultural. }\end{array}$ \\
\hline \multirow{3}{*}{ Objetivos } & $\begin{array}{l}\text { Fortalecer o protagonismo cultural da sociedade brasileira, } \\
\text { valorizando as iniciativas culturais de grupos e comunidades } \\
\text { excluídas e ampliando o acesso aos bens culturais. }\end{array}$ \\
\hline \multirow{2}{*}{ Público-alvo } & $\begin{array}{l}\text { As populações com pouco acesso aos meios de produção, fruição e } \\
\text { difusão cultural ou com necessidade de reconhecimento da identidade } \\
\text { cultural. Adolescentes e jovens expostos à situação de vulnerabilidade } \\
\text { social. }\end{array}$ \\
\hline
\end{tabular}

Fonte: Elaborado pelos autores, a partir de: Araújo e Silva, 2010. 
Como foi dito anteriormente, os Pontos de Cultura são o eixo central do PCV e articulam todas as suas demais ações. Vimos também que suas principais características são a democratização do acesso à cultura e da produção cultural e a valorização das experiências locais e da diversidade cultural. Dessa forma, entendemos que os Pontos de Cultura têm uma estreita proximidade com os princípios que norteiam a economia criativa e que, por isso, devem ser pensados também como territórios criativos.

Para acrescentar visões que corroboram com o pensamento apontado, citamos Barbosa que, ao ampliar e definir o conceito de economia criativa, vai além do que é comumente sabido, como gerar desenvolvimento, capacidades, renda e trabalho, quando afirma que:

Reduzir desigualdades e promover a diversidade também são fermentos desse bolo. Tudo isso se amalgama aos objetivos de inserção de produtos e produtores nos mercados nacionais e internacionais, e também de promoção dos intercâmbios comerciais e tecnológicos, dinamizando e articulando mercados simbólicos. A esses intercâmbios se agregam questões relativas às identidades culturais, ações de caráter lúdico e pedagógico, festivo e celebratório. (BARBOSA, 2011, p. 107)

Já a consultoria da Organização das Nações Unidas para a educação, a ciência e a cultura (UNESCO), em estudo sobre os polos criativos brasileiros, observa:

Relembrando ainda que o que move a Economia Criativa é a criatividade e não o capital, e que ela não lida apenas com produtos, mas com processos, gostaríamos aqui de buscar sua relação com os Objetivos de Desenvolvimento do Milênio (ODMs), firmados enquanto compromisso de diversas nações com um desenvolvimento global. Tais objetivos estão visivelmente ligados à colaboração direta da Economia Criativa, principalmente quando tratamos das participações de comunidades nas formas de organização e de governança diferenciadas, nas pequenas produções econômicas que fazem parte da dinâmica criativa e em outras diversas características que promovem não somente a inclusão econômica, mas principalmente a social, inerente à Economia Criativa e potencialmente presente em todos os países do planeta. (BRASIL, 2012, p. 25)

Esses dois exemplos mostram a proximidade entre as definições, princípios e áreas de abrangência dos Pontos de Cultura e da economia criativa. O que nos é permitido analisar é que a economia criativa poderia ser estimulada e desenvolvida no 
âmbito dos Pontos de Cultura, potencializando não uma economia de mercado, voltada para o lucro e segundo os moldes do sistema capitalista, mas apresentada como uma economia diferente, que funcionaria principalmente através de redes colaborativas e solidárias.

Ao pensar no PCV enquanto uma política cultural para a emancipação das classes populares, Domingues ressalta que:

[...] a realização de uma política pública como o Cultura Viva é importantíssima para a efetivação de uma economia popular de cultura - como de uma economia da cultura popular - que seja capaz de incorporar os trabalhadores da área que não participam do mercado mais consolidado, de forma a tornar ativa a produção cultural das classes populares em redes solidárias de produção da cultura. As estratégias que acompanham as associações de economia solidária são compatíveis com os princípios do desenvolvimento sustentável e com a criação das condições materiais para a inclusão das comunidades tradicionais na vida cultural das nações. Este desafio que o Cultura Viva se coloca é de importância crucial para a sustentabilidade dos Pontos de Cultura e para a ampliação e continuidade do Programa. (DOMINGUES, 2008, p. 169)

\section{O PROJETO DE EXTENSÃO DO IFRN}

A despeito de estarmos a par das discussões da área da cultura, bem como da atuação do MinC, através de seus programas e projetos, nos questionávamos acerca dos Pontos de Cultura da cidade do Natal. Embora conhecêssemos alguns deles, de ouvirmos falar ou de contatos prévios em apresentações públicas, não tínhamos informações sistematizados sobre o desenvolvimento de suas atividades ou ainda análises que dessem conta da sua existência.

Ao mesmo tempo, ao estudarmos a economia criativa, esse novo setor da economia, diretamente relacionado à cultura, nos chamou a atenção a proximidade entre os príncipios da economia criativa e a ideia de territórios criativos para a SEC e o que se compreende enquanto objetivos e/ou ações no âmbito dos Pontos de Cultura.

Nesse contexto, foi pensado o projeto de extensão "Territórios criativos: a dimensão econômica dos Pontos de Cultura de Natal". Este projeto, que tem como objetivo geral identificar as atividades realizadas nos Pontos de Cultura de Natal, potencializando seus aspectos econômicos como forma de contribuir para a sustentabilidade de suas comunidades, se justifica de três maneiras: 1. por sensibilizar 
os grupos envolvidos nos Pontos de Cultura para as potencialidades econômicas das suas atividades e produtos culturais; 2. por levar alunos do curso de Produção Cultural a pensar e desenvolver, conjuntamente com os Pontos de Cultura, ações para os setores criativos; e 3. por iniciar um processo inédito no Estado do Rio Grande do Norte de reconhecimento e desenvolvimento das potencialidades econômicas dos Pontos de Cultura da capital.

Para isso, o projeto tem três metas a serem cumpridas, descridas no Quadro 2, a seguir.

\section{Quadro 2 - Metas do Projeto Territórios Criativos}

\begin{tabular}{|c|l|l|}
\hline METAS & \multicolumn{1}{|c|}{ AÇ̃̃O } & \multicolumn{1}{c|}{ ATIVIDADE } \\
\hline 1 & $\begin{array}{l}\text { Sensibilização dos Pontos de } \\
\text { Cultura atuantes na cidade de } \\
\text { Natal. }\end{array}$ & $\begin{array}{l}\text { Ida a campo para sensibilizar os Pontos de } \\
\text { Cultura quanto a suas potencialidades } \\
\text { econômicas. }\end{array}$ \\
\hline 2 & $\begin{array}{l}\text { Palestra sobre economia } \\
\text { criativa. }\end{array}$ & $\begin{array}{l}\text { Realizar palestra sobre economia criativa para } \\
\text { os Pontos de Cultura sensibilizados na etapa } \\
\text { anterior. }\end{array}$ \\
\hline 3 & $\begin{array}{l}\text { Realizar três Jornadas } \\
\text { Temáticas. }\end{array}$ & $\begin{array}{l}\text { Realizar três Jornadas Temáticas para os } \\
\text { Pontos de Cultura, com os seguintes temas: o } \\
\text { empreendedor, a tecnologia e a gestão. }\end{array}$ \\
\hline
\end{tabular}

Fonte: Elaborado pelos autores.

Até esse momento, desenvolvemos as duas primeiras ações e estamos revendo a terceira, já que embora tenhamos sensibilizado dez $z^{7}$ Pontos e entrado em contato com todos eles para convidá-los para a segunda ação, nenhum deles compareceu à mesa-redonda sobre economia criativa. ${ }^{8}$ Dessa forma, neste segundo semestre do IFRN, pretendemos refazer o planejamento do nosso projeto. É preciso repensarmos, inclusive, as demandas estabelecidas pelos Pontos, já que nos parece que as ações propostas por nós não se mostraram como prioritárias para eles. Cabe ressaltarmos que a adesão dos Pontos ao projeto se deu por meio de um termo de compromisso.

Nesse sentido, talvez seja necessário que modifiquemos nossa forma de abordagem, partindo de outro modo de pensamento, pois, como observou Domingues em sua dissertação:

\footnotetext{
${ }^{7}$ A listagem com o número de Pontos de Cultura da grande Natal a que tivemos acesso foi bem maior, chegando a vinte e dois Pontos. Contudo, não conseguimos contactar todos. E dos que foram contactados, conseguimos sensibilizar dez deles.

${ }^{8}$ A mesa-redonda contou com a participação do professor do Departamento de Políticas Públicas da UFRN, Fernando Cruz; com a consultora na área de cultura do SEBRAE, Cátia Lopes; e com o substituto do representante do MinC Nordeste, Lúcio Rodrigues.
} 
Uma parte importante do processo de implementação do Programa Cultura Viva não está apenas no princípio de transferência de crédito para as classes populares, mas na ativação de uma rede de colaboração entre os Pontos de Cultura, através da disponibilização dos meios de produção a estes grupos. Este é um tema essencial para se pensar a sustentabilidade econômica das iniciativas populares e para a superação do estigma de exclusão do mercado cultural, já que nem todos os bens culturais são capazes de se sustentar segundo as regras rígidas que operam no mercado e na lógica concorrencial própria das leis de incentivo. (DOMINGUES, 2008, p. 167)

Ou seja, não podemos pensar a sustentabilidade econômica das iniciativas populares da mesma maneira como pensamos as iniciativas de negócios do setor privado, pois as regras do mercado não levam em consideração especificidades que são fundamentais para esses grupos, que dizem respeito a sua forma de organização, gestão e a suas necessidades simbólicas e sociais.

Em seu estudo, Domingues defendeu que:

[...] a realização de uma política pública como o Cultura Viva é importantíssima para a efetivação de uma economia popular de cultura - como de uma economia da cultura popular - que seja capaz de incorporar os trabalhadores da área que não participam do mercado mais consolidado, de forma a tornar ativa a produção cultural das classes populares em redes solidárias de produção da cultura. As estratégias que acompanham as associações de economia solidária são compatíveis com os princípios do desenvolvimento sustentável e com a criação das condições materiais para a inclusão das comunidades tradicionais na vida cultural das nações. Este desafio que o Cultura Viva se coloca é de importância crucial para a sustentabilidade dos Pontos de Cultura e para a ampliação e continuidade do Programa. (DOMINGUES, 2008, p. 169)

Assim, até este momento, compreendemos que devemos partir de outro olhar, que leve em consideração essas estratégias. A questão da colaboração e da sustentabilidade são pontos chaves que não conseguimos identificar em nossas idas a campo.

\section{AS ATIVIDADES DESENVOLVIDAS}

Os dez Pontos de Cultura que descrevemos a seguir junto com suas atividades correspondem àqueles em que realizamos a visita de sensibilização para a participação no projeto de Extensão. Naquele momento, apresentamos o projeto, as 
atividades que seriam desenvolvidas e buscamos conhecer um pouco da história e da atuação do Ponto visitado. Os Pontos que aderiram ao projeto assinaram um termo de compromisso que diz respeito ao interesse em participar das atividades, além de permitir o uso das informações obtidas durante as ações para fins acadêmicocientíficos.

Como dito anteriormente, na nossa segunda ação, a mesa-redonda para a exposição e o debate do tema economia criativa, não tivemos a participação de nenhum dos Pontos sensibilizados, mesmo quando alguns já tinham confirmado sua presença. Após essa atividade, que contou com um público externo de quinze pessoas, não tivemos outro contato, pois entramos em recesso e quando retornássemos seria a partir de um novo planejamento. Assim, as informações aqui utilizadas foram obtidas na fase de sensibilização dos Pontos de Cultura. Segue a descrição dos Pontos e das atividades já desenvolvidas.

\section{Rebuliço}

O Ponto de Cultura Rebuliço nasceu no ano de 2008, a partir do convênio entre o MinC e a Fundação José Augusto (FJA).

As principais atividades desenvolvidas pelo Rebuliço são oficinas de formação, capacitação em teatro e produção cultural, e apresentações teatrais que servem de base para o fomento cultural do território. O Ponto também disponibiliza o espaço da sede para a realização das atividades de outros grupos artísticos.

O Ponto busca dar um retorno de suas atividades para a comunidade na qual está localizado, ao movimentar e agitar o cenário cultural local, oferecendo festivais e mostras artísticas, shows musicais, apresentações de teatro e momentos de convivência, contribuindo, assim, para a democratização do acesso, a formação de público e a valorização dos artistas do nosso Estado.

Ao entrevistarmos o coordenador do Rebuliço, Rodrigo Bico, percebemos que o Ponto busca a sua sustentabilidade através da elaboração de projetos para outros editais de cultura.

\section{Mãos nas Artes}

O Ponto de Cultura Mãos nas Artes surgiu no ano de 2008, em convênio entre o MinC e a FJA. 
O Mãos nas Artes nasceu a partir do grupo Artes e Traquinagens, com o objetivo de desenvolver atividades como oficinas de teatro de rua, palhaços e mamulengos, e a confecção de figurinos, adereços e bonecos, para alunos de escolas públicas da comunidade e suas mães.

Alguns grupos artísticos como a Charanga do Riso (palhaços com repertório musical infantil), o forró pé de serra (zabumba, triângulo, sanfona e voz), o Bregão e ainda a confecção de figurinos e adereços feitos sob encomenda são atividades importantes para a sustentabilidade do grupo Artes e Traquinagens. ${ }^{9}$

\section{Pau e Lata}

O Ponto de Cultura Pau e Lata, que tem convênio direto com o MinC, desde 2010, tem como principal atividade a educação musical em escolas públicas. O grupo existe desde 1996 e, em Natal, tem sua sede na Universidade Federal do Rio Grande do Norte (UFRN). Já foi projeto de extensão da UFRN e hoje é um grupo permanente da Universidade.

O Pau e Lata considera-se autossustentável e possui várias parcerias firmadas, contudo, não se reconhece como um grupo artístico que apenas comercializa o seu show. Não há, portanto, constantes entradas financeiras, como, por exemplo, o pagamento de cachês.

O material utilizado para a construção dos instrumentos (muitos feitos a partir da reutilização de tonéis e tambores de plástico) é doado e o grupo também inscreve projetos em editais públicos e privados, com a finalidade de custear os materiais necessários ao trabalho desenvolvido, bem como para a circulação do grupo.

Atualmente, o Pau e Lata possui dezenove núcleos que trabalham em conjunto, mesmo à distância, e tomam decisões de forma coletiva. Os núcleos têm a oportunidade de se reunir, a cada dois anos, durante a Semana de Ciência, Tecnologia e Cultura (CIENTEC) da UFRN.

\section{Giratório}

O grupo Gira Dança surgiu em 2005, através de uma proposta dos bailarinos Anderson Leão e Roberto Moraes, após suas respectivas saídas da Roda Viva Companhia de Dança, projeto de Extensão da UFRN.

\footnotetext{
${ }^{9}$ Existe uma diferenciação entre o Ponto de Cultura e o grupo existente anterior ao PCV.
} 
O Ponto de Cultura Giratório surgiu em 2008, através de convênio entre o MinC e a FJA. Inicialmente, foram propostas oficinas de criação em dança e artes manuais, para pessoas com necessidades especiais e seus familiares, na Associação de Orientação aos Deficientes (Adote). As oficinas, ministradas por dois dos bailarinos, foram a primeira fase para a inserção dos participantes no Gira Dança. No segundo ano do convênio, não houve o repasse de verba. Assim, as oficinas passaram a acontecer na sede do Gira Dança. Ao final, houve a montagem do espetáculo Terreiro Lumiara, junção de dança contemporânea com a dança popular do cavalo marinho.

O Ponto de Cultura possui um planejamento de projetos a serem realizados a curto e longo prazo. Assim, conseguem montar e apresentar seus espetáculos durante todo o ano. Hoje, o grupo consegue cobrar um valor, por menor que seja, para a apresentação de seus espetáculos, o que considera uma conquista. No espaço do Ponto de Cultura funciona uma pequena loja onde são vendidos suvenires da Companhia.

O grupo oferece oficinas, pagas e gratuitas, de dança latina, dança contemporânea e de iniciação à fotografia. Mesmo com algumas dificuldades, por se localizar em um bairro da cidade com uma imagem negativa, de abandono e insegurança, o grupo vem alcançando um status de solidez na cena cultural de Natal.

\section{Barracão Mambembe}

O Ponto de Cultura iniciou suas atividades em 2010, voltadas para a formação de dois novos grupos de teatro, no interior do Estado do Rio Grande do Norte. Seus trabalhos estão $80 \%$ concentrados no interior e $20 \%$ na capital. Assim, são realizadas oficinas teóricas e práticas e a partir disso é pensada a formação de um grupo de teatro.

O Barracão Mambembe está ligado ao grupo de teatro Clowns de Shakespeare, existente há vinte anos, e apresenta características de solidez na cena cultural da cidade. O grupo busca aproximação com a comunidade através da formação de público para os espetáculos e das oficinas abertas ao público, realizadas na sede. Além das atividades oferecidas em Natal, o grupo também desenvolve seu trabalho em mais duas cidades do Estado.

O Clowns de Shakespeare mantém-se através de editais, principalmente públicos, e tem como ideologia a cultura como uma necessidade do homem. Dessa forma, acredita que o Estado também é responsável por disponibilizar recursos para 
que a população tenha acesso a produções culturais. Todos os seus componentes vivem do trabalho artístico, sendo esse o seu principal meio de sustento.

\section{Avança Bom Pastor}

O Ponto de Cultura, criado em 2009, em convênio entre MinC e a FJA, surge a partir da Associação Cultural do Bom Pastor, buscando valorizar, desenvolver, preservar e difundir as manifestações folclóricas do bairro Bom Pastor, em Natal, envolvendo jovens e idosos nas práticas da cultura popular.

O Avança Bom Pastor promove ações como oficinas de dança, teatro e folclore; realiza eventos em sua sede, em uma praça do bairro e em outros locais da comunidade. Realizam também um cortejo anual, no sete de setembro, e possuem projetos de circulação nas escolas públicas. Nos meses de junho e julho, apresentam a quadrilha junina, Popular Beijoqueiros, existente há vinte e cinco anos, em diferentes festas de São João.

Além dessas ações, são realizadas atividades como balé, teatro, dança popular, grupos folclóricos, Boi de Reis, Pastoril, capoeira e ginástica, para os idosos da comunidade. A Associação também inscreve projetos em editais públicos e privados.

\section{Boi Vivo}

O Ponto de Cultura Boi Vivo foi oficializado em 2008, em convênio com o MinC e a FJA. O Boi Vivo descende da Associação República das Artes, composta por vários grupos que movimentaram a cena cultural da cidade de Natal.

Buscando preservar e valorizar a cultura popular do Estado, Mestre Elpídio, falecido em 2010, deixou como herança técnicas de confecção de máscaras das figuras do Boi de Reis. Assim, o Boi Vivo desenvolve pesquisas sobre os fazeres culturais, as andanças, os personagens, os figurinos e adereços do Boi de Reis do Rio Grande do Norte.

As principais atividades do Ponto são oficinas de dança para crianças (Boi de Reis mirim), que surge com o intuito de repassar os conhecimentos e a tradição dos dançantes do Boi de Reis. Há também um Boi de Reis formado por jovens, com idade entre treze e vinte e três anos, e ainda um grupo de forró de rabecas.

\section{Cascudo: canta lá que eu canto cá}

O Ponto de Cultura surgiu em 2008, quando foi assinado o termo de convênio 
entre o MinC e a FJA, contudo só recebeu o título e começou a desenvolver suas atividades, em 2010.

O grupo Cascudo: canta lá que eu canto cá desenvolve ações que permeiam o universo da contação de histórias da cultura potiguar. As principais atividades desenvolvidas são a pesquisa, a construção de laboratórios criativos, que se realizam através das oficinas de contação de histórias, da construção de bonecos de espuma, da personificação de personagens e das rodas de contação de histórias, que são oferecidas à comunidade. Essas atividades somadas às apresentações da dupla de palhaços são formas de garantir a sustentabilidade financeira do Ponto.

\section{Sons da Vila}

O Ponto de Cultura Sons da Vila é conveniado diretamente com o MinC, desde 2004, e busca promover o desenvolvimento pessoal, o empoderamento social e a transformação do local onde está inserido, através do conhecimento e do fazer compartilhado. O espaço, existente há vinte anos, desenvolve atividades para mulheres, crianças e adolescentes, tais como oficinas de leitura, de pintura, de modelagem, de corte e costura, de colagem em tecidos e de gastronomia. Além disso, possui uma biblioteca para uso da comunidade.

Ao estimular a criatividade nesses fazeres, tornando-os singulares e originais, o Ponto de Cultura fortalece as identidades locais. Assim, há dez anos, surgiu o Coletivo Dez Mulheres. Esse coletivo, voltado para a independência das mulheres da Vila de Ponta Negra, criou a Feira e a loja colaborativa, Feito na Vila, além de um espaço gastronômico, ações que reafirmam as potências do local, possibilitando o empoderamento e a independência dessa população.

\section{Mulheres Arteiras}

O Ponto de Cultura Mulheres Arteiras é conveniado com o MinC, em parceria com a FJA, e iniciou suas atividades em 2010. Desenvolve ações artístico-culturais, com jovens e idosos das comunidades de Mãe Luíza, Alto do Juruá e Santos Reis, na região leste de Natal.

Mulheres Arteiras busca a participação ativa das comunidades, ao reafirmar princípios de liberdade, autonomia, solidariedade e respeito à diversidade, através de discussões sobre protagonismo juvenil, cidadania e valorização do indivíduo na sociedade. 
As principais atividades realizadas são oficinas artísticas e culturais, tais como percussão, rádio, economia solidária, fotografia, produção e edição de vídeos. As atividades oferecidas permitem que as comunidades da Zona Leste tenham uma formação ampliada, tanto pessoal quanto profissional, social e culturalmente.

No Ponto existe uma biblioteca, na qual são realizadas ações de incentivo à leitura. Além disso, Mulheres Arteiras também realiza programações culturais, como o Cine Cult, o Arte na Praça, o Café com Arte, o sarau e debates socioculturais, em espaços públicos das comunidades.

A sustentabilidade do Ponto é pensada a partir de parcerias com a UFRN e o IFRN e da inscrição de projetos em editais de cultura.

\section{CONSIDERAÇÕES FINAIS}

Atualmente, passados dez anos de existência do Programa Cultura Viva, muitos resultados locais ainda são desconhecidos. No Rio Grande do Norte, não temos informação de análises ou avaliações dos Pontos de Cultura do Estado, ou ao menos da sua capital. Em um primeiro momento, o que nos despertou interesse foi especialmente a questão da sustentabilidade dos Pontos de Cultura, da sua autonomia financeira e da inclusão econômica de seus participantes. Contudo, ao nos aproximarmos da sua realidade, repensamos a nossa forma de abordagem e de raciocínio.

De início, acreditamos que a sustentabilidade dos Pontos de Cultura passa necessariamente pela questão financeira, mas condicionarmos a sua existência apenas a esse aspecto seria restringir um universo muito mais amplo, que engloba processos criativos, educativos e sociais, e estabelece redes de troca de experiências, de conhecimentos e de solidariedade, que vão além das trocas econômicas. Assim, como apontado pelo próprio MinC:

É preciso rever o pensamento econômico convencional e avançar na idéia da construção do 'capital social', reexaminando as relações entre cultura e desenvolvimento. O Programa Cultura Viva pretende discutir e encontrar alternativas de desenvolvimento humano sustentável junto às comunidades e movimentos sociais que visa atingir. O programa potencializa a criação e a produção local, gerando produtos culturais que vão do artesanato à produção de moda, da montagem de uma peça de teatro à produção de um audiovisual. (BRASIL, 2010, p. 30) 
Contudo, até o presente momento, não conseguimos visualizar ações de circulação entre a própria rede dos Pontos de Cultura do Rio Grande do Norte, o que para nós foi identificado como uma situação bastante frágil.

Em um segundo momento, constatamos que todos os Pontos aqui analisados já existiam antes do PCV. Isso nos fez perceber algo que nos causou certo estranhamento: o fato dos Pontos se colocarem de forma distinta dos grupos artísticos que já existiam quando do convênio com o MinC ou da parceria do MinC com a FJA. Para nós, a consequência disso é que as atividades desenvolvidas pelos Pontos e pelos grupos anteriormente existentes são pensadas, muitas vezes, de maneira separada. Esta realidade nos traz um terceiro dado.

A maioria das atividades realizadas pelos Pontos de Cultura são oficinas, mas não percebemos uma produção que, como colocado pelo MinC, criaria possibilidades de desenvolvimento de uma economia local. Embora esse potencial exista, para que os Pontos possam ser reconhecidos como territórios criativos, são necessárias algumas ações de incentivo no âmbito das políticas públicas de cultura. De acordo com Vilutis, ao abordar as ações do PCV de fomento à economia da cultura, “[...] dessas três dimensões da cultura [simbólica, cidadã e econômica], a dimensão econômica dos Pontos de Cultura foi a menos fomentada no programa enquanto política cultural" (VILUTIS, 2011, p. 3). Em Natal, essa constatação é bastante evidente, conforme observado na descrição das atividades dos Pontos.

Por último, pudemos constatar que, embora muitos dos Pontos visitados busquem formas de sustentabilidade independentes do repasse de verba do $\mathrm{PCV}$, não existe o desenvolvimento de uma rede de economia solidária entre os Pontos, em Natal ou no Rio Grande do Norte.

Esperamos que o desenvolvimento deste projeto possibilite maneiras para que os Pontos de Cultura possam superar as dificuldades percebidas no primeiro momento e que possamos contribuir para que eles se percebam e sejam reconhecidos enquanto territórios criativos.

\section{Referências}


ARAÚJO, Herton Ellery; SILVA, Frederico A. Barbosa da. Cultura Viva: avaliação do programa arte educação e cidadania. Brasília, DF: IPEA, 2010.

BARBOSA, Frederico. Economia criativa: políticas públicas em construção. In: BRASIL. Ministério da Cultura. Plano da Secretaria da Economia Criativa: políticas, diretrizes e ações, 2011 - 2014. Brasília, DF: Ministério da Cultura, 2011. p. 107-111.

BARBOSA, Frederico; CALABRE, Lia (orgs.). Pontos de Cultura: olhares sobre o Programa Cultura Viva. Brasilia, DF: IPEA, 2011.

BRASIL. Ministério da Cultura. Lei Cultura Viva. Disponível em: <http://www.cultura.gov.br/cultura-viva1>. Acesso em: 20 out. 2014.

Ministério da Cultura. Programa Cultura Viva - Documento base. Brasília, DF, Ministério da Cultura, 2013.

Ministério da Cultura. Programa Nacional de Cultura, Educação e Cidadania - Cultura Viva: autonomia, protagonismo e fortalecimento sóciocultural para o Brasil. Brasília, DF: Ministério da Cultura, 2010.

Plano da Secretaria da Economia Criativa: políticas, diretrizes e ações, 2011 - 2014. Brasília, DF, Ministério da Cultura, 2011.

Polos criativos: um estudo sobre os pequenos territórios criativos brasileiros. Brasília, DF: Ministério da Cultura, 2012.

CANEDO, Daniele et al. Políticas públicas de cultura: os mecanismos de participação social. In: RUBIM, Antonio Albino Canelas. (Org.). Políticas culturais no governo Lula. Salvador: EDUFBA, 2010. p. 25-47.

DINIZ, Luisa Maria Rodrigues. Análise das dimensões da sustentabilidade dos Pontos de Cultura em Pernambuco. 2009, 109 p. Dissertação (Mestrado em Administração) - Centro de Ciências Sociais Aplicadas, Universidade Federal de Pernambuco, Recife, 2009.

DOMINGUES, João Luiz Pereira. Programa Cultura Viva: políticas culturais para a emancipação das classes populares. 2008. 216 p. Dissertação (Mestrado em Políticas Públicas e Formação Humana) - Faculdade de Educação, Universidade do Estado do Rio de Janeiro, Rio de Janeiro, 2008.

INSTITUTO DE PESQUISA ECONÔMICA APLICADA. Cultura Viva: as práticas de Pontos e Pontões. Brasília, DF: IPEA, 2011. 
LACERDA, Alice Pires de; MARQUES, Carolina de Carvalho; ROCHA, Sophia Cardoso. Programa Cultura Viva: uma nova política do Ministério da Cultura. In: RUBIM, Antonio Albino Canelas. (Org.). Políticas culturais no governo Lula. Salvador: EDUFBA, 2010. p. 111-131.

SILVA, Frederico A. Barbosa da. Economia e política cultural: acesso, emprego e financiamento. Brasília, DF: Ministério da Cultura, 2007.

VILUTIS, Luana. Pontos de cultura e economia solidária: aproximações e possibilidades. Disponível em: $<$ http://culturadigital.br/politicaculturalcasaderuibarbosa/2011/11/06/artigos-do-iiseminario-internacional-de-politicas-culturais/>. Acesso em: 20 out. 2014. TURINO, Célio. Ponto de cultura: o Brasil de baixo para cima. 2. ed. São Paulo: Anita Garibaldi, 2010.

TURINO, Célio. Por uma cultura viva desencadeando o Brasil profundo. Disponível em: <http://www.forumrio.uerj.br/documentos/revista_15/15_ppc_CelioTurino.pdf>. Acesso em: 24 mar. 2015. 